\title{
Germinação de sementes de Conyza canadensis e $C$. bonariensis em função da presença de alumínio no substrato
}

\author{
Germination of Conyza canadensis and $C$. bonariensis seeds under presence of \\ aluminum in the substrate
}

Oscar Mitsuo Yamashita ${ }^{\mathrm{I}}$ Sebastião Carneiro Guimarães ${ }^{\mathrm{II}}$

- NOTA -

\section{RESUMO}

\begin{abstract}
A germinação das sementes pode ser fortemente influenciada pelas condições ambientais, afetando o estabelecimento de comunidades florísticas. As plantas daninhas, apesar das características de rusticidade $e$ capacidade de suas sementes germinarem em condições de estresse ambiental, podem sofrer o efeito direto da presença de elementos tóxicos no substrato. O alumínio, presente em solos com pH baixo, pode interferir negativamente no processo germinativo de sementes de espécies cultivadas e também de plantas daninhas. No presente trabalho, objetivou-se estudar o efeito tóxico da presença de alumínio no substrato durante a germinação de sementes de Conyza. A germinação foi reduzida pela presença de alumínio no substrato, havendo decréscimos significativos a partir de $1,5 \mathrm{cmol}_{c} \mathrm{dm}^{-3}$ para as sementes de ambas as espécies, enquanto a velocidade de germinação foi prejudicada a partir da menor concentração $\left(0,5 \mathrm{cmol}_{c} \mathrm{dm}^{-3}\right)$ de alumínio testada. Esses resultados demonstram que as sementes de ambas as espécies são sensíveis à presença de alumínio no substrato de germinação.
\end{abstract}

Palavras-chave: buva, voadeira, estresse, tolerância.

\section{ABSTRACT}

Seed germination can be greatly influenced by environmental conditions, which affects the establishment of floristic communities. The weeds, although they had features as hardiness and its ability to germinate seeds under environmental stress conditions, may experience the direct effect of the presence of toxic elements in the substrate. Aluminum, present in soils with low $\mathrm{pH}$ can negatively impact the germination of seeds of crop species and weeds. This research aimed to study the toxic effect of aluminum presence in the substrate during seed germination of Conyza. Germination was reduced by the presence of aluminum in the substrate, with significant decreases from $1.5 \mathrm{cmol}_{c} \mathrm{dm}^{-3}$ for the seeds of both species. The germination rate was affected from the lower concentration of aluminum tested $\left(0.5 \mathrm{cmol}_{c} \mathrm{dm}^{-3}\right)$. These results demonstrate that the seeds of both species are sensitive to the presence of aluminum in substrate germination.

Key words: horseweed, fleabane, stress, tolerance.

O primeiro estágio de desenvolvimento das plantas é a germinação das sementes e esta é influenciada diretamente pelas condições ambientais. Muitas dessas condições estão relacionadas com as propriedades do substrato no qual a semente é dispersa. A presença de elementos tóxicos no solo é uma característica muito comum em diversas regiões do mundo, inclusive nas regiões tropicais (KOSZO, 2006).

Fatores como temperatura, luz e disponibilidade hídrica do substrato na germinação das sementes têm sido amplamente estudados (MAYER \& SHAIN, 1974). No entanto, pouca atenção tem sido dada à presença de elementos tóxicos no meio que serve de substrato para as sementes. O alumínio é um elemento que se torna disponível em condições de $\mathrm{pH}$ baixo, sendo que, em solo ácido, o elemento solubilizase em $\mathrm{Al}^{3+}$, exercendo efeito tóxico sobre a germinação e o desenvolvimento das espécies vegetais (ROUT et al., 2001; CUSTÓDIO et al., 2002; MA \& FURUKAWA,

'Departamento de Agronomia, Campus Universitário de Alta Floresta, Universidade do Estado de Mato Grosso (UNEMAT), Rod. MT 208, km 147, 78580-000, Alta Floresta, MT, Brasil. E-mail: yama @unemat.br. Autor para correspondência.

"Faculdade de Agronomia e Medicina Veterinária, Campus Universitário de Cuiabá, Universidade Federal de Mato Grosso (UFMT), Cuiabá, MT, Brasil. 
2003; HARTWIG et al., 2007). A lixiviação do solo pode resultar, em certos casos, em solos tão ácidos que a germinação e o desenvolvimento inicial de muitas espécies tornam-se impossíveis (ROY et al., 1988; SOUZA FILHO \& DUTRA, 1998).

A presença de C. canadensis e $\boldsymbol{C}$. bonariensis é comum em áreas de cultivo com sistema de semeadura direta (SSD) na região do cerrado brasileiro, onde os teores originais de alumínio no solo são altos, causando prejuízos pela competição com espécies cultivadas, principalmente a soja. Entretanto, não são encontrados na literatura relatos sobre interferência da presença de alumínio no solo na germinação das sementes dessas duas espécies. Diante do exposto, o objetivo deste trabalho foi estudar o a germinação das sementes de $\boldsymbol{C}$. canadensis e $\boldsymbol{C}$. bonariensis na presença de diferentes níveis de alumínio no substrato.

Desenvolveu-se um experimento em delineamento experimental inteiramente casualizado no esquema fatorial $2 \times 5$, com duas espécies $(\boldsymbol{C}$. canadensis e C. bonariensis) e quatro soluções aquosas de $\mathrm{Al}_{2}\left(\mathrm{SO}_{4}\right)_{3} .18 \mathrm{H}_{2} \mathrm{O}$ (pm 666), nas concentrações de 0,5; 1,$0 ; 1,5 \mathrm{e} 2,0 \mathrm{cmol}_{\mathrm{c}} \mathrm{dm}^{-3}$; mais a solução controle (água deionizada), todas com quatro repetições.

Semearam-se 50 sementes sobre duas folhas de papel germibox, no interior de caixas tipo gerbox umedecidas, utilizando-se um volume de solução equivalente a 2,5 vezes o peso seco do papel. As caixas foram distribuídas aleatoriamente dentro de câmara de germinação tipo BOD, regulada à temperatura constante de $25^{\circ} \mathrm{C}$ e fotoperíodo de 12 horas. Diariamente, foram trocados os papéis e a solução de umedecimento até o 20 o dia da montagem do experimento. $\mathrm{O}$ número de sementes germinadas foi contado diariamente até os 20 dias após a semeadura. Foram consideradas germinadas as sementes cuja plântula originada estava com raiz $\geq 2,0 \mathrm{~mm}$. Com base nos dados de germinação diária, calculou-se a germinação acumulada no período experimental e o índice de velocidade de germinação (IVG), confeccionando-se gráficos de regressão para a apresentação dos resultados obtidos.

A germinação das sementes de Conyza foi influenciada pelas concentrações da solução de alumínio, sendo que também ocorreu interação significativa entre as espécies e as concentrações de alumínio. Assim, observou-se que a presença de alumínio no substrato interferiu na germinação final de sementes de Conyza a partir de $1,5 \mathrm{cmol}_{\mathrm{c}} \mathrm{dm}^{-3}$, havendo redução de $24 \%$ na germinação das sementes de $\boldsymbol{C}$. canadensis e $30 \%$ de $\boldsymbol{C}$. bonariensis nessa concentração, em relação às sementes da testemunha. $\mathrm{Na}$ maior concentração estudada $\left(2,0 \mathrm{cmol}_{\mathrm{c}} \mathrm{dm}^{-3}\right)$, a redução foi ainda maior, chegando a 35\% e $60 \%$ de redução para $\boldsymbol{C}$. canadensis e $\boldsymbol{C}$. bonariensis, respectivamente (Figura 1A).
Esses resultados confirmam os obtidos por SOUZA FILHO \& DUTRA (1998), que observaram redução na germinação total de sementes de Calopogonium mucunoides em substrato com concentração de alumínio a partir de $2,0 \mathrm{cmol}_{\mathrm{c}} \mathrm{dm}^{-3}$. Entretanto, observou-se tolerância ao elemento para sementes de algumas espécies como Pueraria phaseoloides (CARVALHO, 1985), Cassia tora e Urena lobata (SOUZA FILHO et al., 1998) e Erythrina speciosa (KOSZO, 2006).

Mesmo em menores concentrações, observou-se redução no desenvolvimento do sistema radicular das plântulas originadas das sementes consideradas germinadas, em relação à testemunha. Além disso, as raízes se encontravam com necrose em sua extremidade que, em alguns casos, evoluíram para a morte da plântula em poucos dias. A possível explicação para esse fato pode ser dada pelos relatos de CUSTÓDIO et al. (2002), de que o alumínio reagiria com cadeias de ácido poligalacturônico das paredes das células jovens, formando compostos pécticos "errados" (substituição ou deslocamento de $\mathrm{Ca}$ ) o que resultaria na perda de elasticidade celular. Nessa condição, a região meristemática da extremidade da raiz teria uma grande quantidade de células com dois núcleos, indicando a paralisação no processo de divisão celular.

O índice de velocidade de germinação foi influenciado pela espécie e pela concentração isoladamente, não havendo interação entre os fatores estudados. A resposta na velocidade de germinação, quando da presença de $\mathrm{Al}^{3+}$, foi diferente para as sementes das espécies estudadas, sendo maior para aquelas de $\boldsymbol{C}$. canadensis em comparação às de $\boldsymbol{C}$. bonariensis, demonstrando que essas últimas são mais sensíveis tanto na sua velocidade como na porcentagem de germinação, pois a sua porcentagem final foi menor que as da outra espécie.

À medida que a concentração de $\mathrm{Al}^{3+}$ aumentou, a velocidade de germinação decresceu (Figura 1B), sendo a maior redução na velocidade de germinação entre as sementes da testemunha e daquelas submetidas à menor concentração estudada. A partir daí, à medida que a concentração aumentou, a velocidade sofreu um decréscimo. Isso demonstra que o alumínio, mesmo em baixa concentração, foi responsável pela diminuição da velocidade de germinação. Dessa forma, percebe-se que a acidificação do meio, provocada pela presença de alumínio na solução de embebição pode ter potencializado a redução na resposta germinativa das sementes de Conyza, influenciando diretamente a velocidade de germinação. Resultados semelhantes foram observados em Cucumis sativus e Eugenia brasiliensis, quando colocadas para germinar em substrato umedecido com cloreto de alumínio (KOSZO, 2006). 


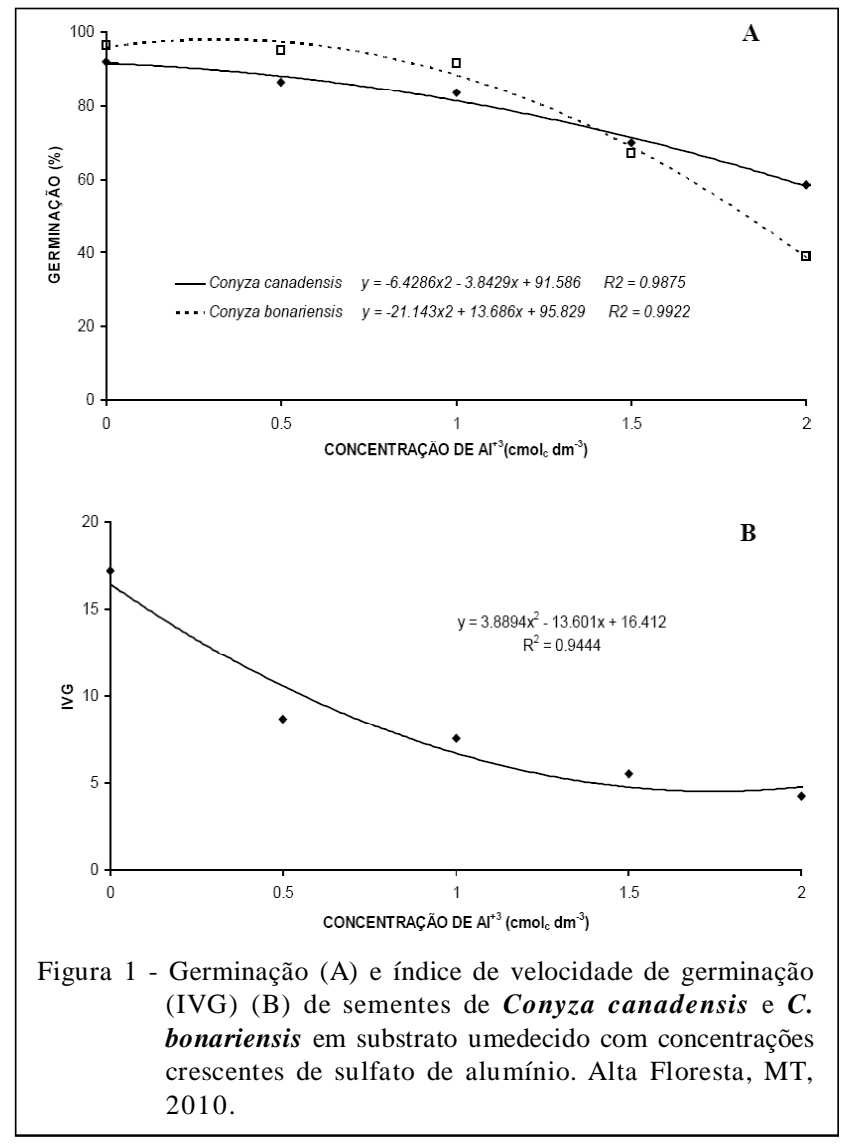

Pelos resultados, constata-se que a presença de alumínio no substrato prejudica a germinação e o vigor das sementes de Conyza em concentrações superiores a $1,5 \mathrm{cmol}_{\mathrm{c}} \mathrm{dm}^{-3}$.

\section{REFERÊNCIAS}

CARVALHO, M.M. Melhoramento da produtividade das pastagens através de adubação. Informe Agropecuário, Belo Horizonte, v.11, n.132, p.23-32, 1985.

CUSTÓDIO, C.C. et al. Estresse por alumínio e por acidez em cultivares de soja. Scientia Agricola, Piracicaba, v.59, n.1, p.145-153, 2002. Disponível em: <http://www.scielo.br/pdf/ sa/v59n1/8087.pdf $>$. Acesso em: 29 abr. 2009. doi: 10.1590/ S0103-90162002000100021.

HARTWIG, I. et al. Mecanismos associados à tolerância ao alumínio em plantas. Semina Ciências Agrárias, Londrina, v.28, n.2, p.219-228, 2007. Disponível em: <http://www.uel.br/ revistas/uel/index.php/semagrarias/article/viewFile/3431/2790>. Acesso em: 22 abr. 2009.

KOSZO, C.R.R. Germinação de sementes de Erythrina speciosa Andr. E Eugenia brasiliensis Lam. em meio ácido. 2006. 84f. Dissertação (Mestrado em Biodiversidade Vegetal e Meio Ambiente) - Instituto de Botânica, São Paulo, SP.
MA, J.F.; FURUKAWA, J. Recent progress in the research of external Al detoxification on higher plants: a minireview. Journal of Inorganic Biochemistry, New York, v.97, n.1, p.46-51, 2003.

MAYER, A.M.; SHAIN, Y. Control of seed germination. Annual Review of Plant Physiology, Palo Alto, v.25, n.1, p.167-173, 1974.

ROUT, G.R. et al. Aluminium toxicity in plants: a review. Agronomie, Paris, v.21, n.1, p.3-21, 2001. Disponível em: <http:// www.plantstress.com/articles/toxicity_i/A1\%20toxicity.pdf>. Acesso em: 17 maio, 2009.

ROY, A.K. et al. Some aspects of aluminum toxicity in plants. Botanical Reviews, New York, v.54, n.2, p.145-178, 1988. Disponível em: <http://www.springerlink.com/index/E5X4H38618484169.pdf>. Acesso em: 13 maio, 2009. doi: 10.1007/BF02858527.

SOUZA FILHO, A.S.; DUTRA, S. Germinação de sementes de calopogônio (Calopogonium mucunoides). Pasturas Tropicales, Cali, v.20, n.3, p.26-30, 1998. Disponível em: <http://ciatlibrary.ciat.cgiar.org/Articulos_Ciat/PAST2035.pdf>. Acesso em: 05 jan. 2011.

SOUZA FILHO, A.S. et al. Efeitos de diferentes substratos e da profundidade de semeadura na germinação de sementes de matapasto e malva. Planta Daninha, Viçosa, v.16, n.1, p.67-74, 1998. Disponível em: <http://www.scielo.br/pdf/pd/v16n1/ a07v16n1.pdf>. Acesso em: 29 maio, 2009. doi: 10.1590/ S0100-83581998000100007. 